\title{
Chabolismo indignante: el hábitat de los que sobran
}

\section{Ana Sugranyes *}

\section{Resumen}

A pesar de todos los tratados internacionales de derechos humanos, en el mundo mil millones de personas viven en la indignidad de concentraciones homogéneas de pobreza, urbanas y rurales. El enfoque de este análisis prioriza el estudio de las capacidades de los habitantes en los asentamientos precarios: las distintas formas de lucha diaria por el derecho a un lugar donde vivir en paz y dignidad. El hábitat de los que sobran es un tema de personas, de organizaciones sociales, de sociedad y de territorio, más allá de las condiciones físicas de las viviendas y de las barriadas.

Este artículo recoge reflexiones sobre la indignidad del hábitat de comunidades que aspiran a integrarse a la ciudad para vivir bien, pero sufren costes sociales, económicos, políticos, ciudadanos, psicológicos, medioambientales, físicos y monetarios; se ven estigmatizados por su marginación, exclusión e informalidad y logran sobrevivir solo superando día a día el miedo. Se estructura en torno a un análisis del problema de la integración y marginación socio-espacial; una descripción de situaciones marcadas por la diversidad de condiciones y contextos, en América Latina, África y USA; una referencia a opciones muy diversas de intervención y alternativas basadas en el enfoque de los derechos colectivos, el derecho a la ciudad.

\section{Palabras clave}

Asentamientos Humanos; Derecho A La Vivienda y a la Tierra; Derecho a la Ciudad

\section{Abstract: Indignant Slums: The Habitat of those Left Over}

In spite of international human rights treaties, one billion people live in in the indignity of homogenous concentrations of poverty, in urban and rural areas alike. This analytical approach focuses on studying the capacities of inhabitants living in precarious settlements: the various forms of their daily struggles for the right to live in a place in peace and with dignity. Beyond the physical conditions of housing and slums, the habitat of those left over concerns people, social organizations, society and territory.

This article reflects upon the undignified living conditions of communities who aspire to integrate themselves in the city in order to live well, but who in turn suffer social, economic, political, citizenship, environmental, physical and monetary costs and setbacks and are stigmatized for their marginalization, exclusion, and informality, only managing to survive by overcoming their fears. It is structured around an analysis of the problem of housing integration and marginalization; a description of situations marked by the diversity of conditions and contexts, in Latin America, Africa and USA; references to very diverse options for intervention; and alternatives based on a collective rights approach, the right to the city.

\section{Key words}

Human Settlements; Housing and Land Rights; Right to the City 
Únete al baile de los que sobran

Nadie nos va a echar de más

Nadie nos quiso ayudar de verdad

Baile de los que sobran, Los Prisioneros (1986)

"Vengo sosteniendo que la crisis actual del capitalismo es más que coyuntural y estructural. Es terminal. ¿Ha llegado el final del genio del capitalismo para adaptarse siempre a cualquier circunstancia? Soy consciente de que pocas personas sostienen esta tesis. (...) Al agravarse la crisis crecerán en todo el mundo las multitudes que no aguanten más las consecuencias de la súper explotación de sus vidas y de la vida de la Tierra y se rebelen contra este sistema económico que ahora agoniza, no por envejecimiento, sino por la fuerza del veneno y de las contradicciones que ha creado, castigando a la Madre Tierra y afligiendo la vida de sus hijos e hijas".

Leonardo Boff, “¿Crisis terminal del capitalismo?”, ATTAC, España, 27 de junio de 2011

\section{Introducción}

A menudo me pregunto por qué y cómo hemos llegado a hablar de chabolismo, esta palabra de origen vasco que sólo se usa en España, que corresponde a los términos slum en inglés - de origen irlandés- y bidonville en francés - una traducción literal nos podría llevar al bidón urbano-, y que en el transcurso de los años ha ido cambiando de connotación. De referirse en primera instancia a casuchas de muy mala calidad, ha llegado a denominar el hábitat de mil millones de personas en el mundo, concentraciones homogéneas de pobreza, urbanas y rurales, contrapuestas a todos los tratados internacionales de derechos humanos, políticos, cívicos, económicos, sociales y culturales.

Llevamos muchos lustros trabajando mano a mano con los habitantes de asentamientos humanos precarios, denominación que evoca una gran variedad de historias y contextos; por ejemplo, en América Latina, tenemos entre otros ba- rracones, barriadas, callampas, campamentos, campos de refugiados -temporales y permanentes-, cantegriles, cités, conventillos, cuarterías, favelas, hoteles, limonadas, mesones, palomares, poblaciones, pueblos jóvenes, tomas, tugurios, villas. Estos habitantes, o pobladores - usando ahora una palabra latinoamericana que agrupa a quienes viven en los barrios populares- se caracterizan por tener que luchar a diario por el derecho a un lugar donde vivir en paz y dignidad.

Más allá de las condiciones físicas de las viviendas y de las barriadas, el hábitat de los que sobran es un tema de personas, de organizaciones sociales, de sociedad y de territorio.

Este artículo analiza la indignidad de las condiciones habitacionales ${ }^{1}$ de las comunidades que aspiran integrarse al buen vivir ${ }^{2}$ de la ciudad, pero sufren todo tipo de costes sociales, económicos, políticos, ciudadanos, psicoemocionales, biológicos, medioambientales, físicos y monetarios por vivir la estigmatización de la marginación, la exclusión, la informalidad, la ilegalidad, la rotería, la astucia, la maña, la fullería, y que sobreviven superando día a día sus temores.

El desarrollo de estas ideas se estructura en torno a un análisis de las situaciones de integración y de marginación habitacional. El problema de los asentamientos humanos no se puede entender desde la visión apocalíptica del Planet of Slums, sino que en función de la dignidad humana y del

\footnotetext{
${ }^{1}$ Habitacional: Término latinoamericano relacionado al hábitat; aplicado en materia de políticas públicas del hábitat. Observar su uso, por ejemplo, en documentos de la CEPAL, Comisión Económica para América Latina y el Caribe, Naciones Unidas. El buen vivir constituye un paradigma de sociedad sustentable basado en el acoplamiento equilibrado y equitativo entre economía y naturaleza, de tal suerte que la vida entera esté garantizada para la especie humana. Para más información, consultar el artículo "El buen vivir, más allá del desarrollo" de Patricio Carpio Benalcázar, Ecuador, accesible en: <http://alainet.org/active/24609\&lang=es >
} 
empoderamiento ${ }^{3}$ de los que sobran; un proceso de fortalecimiento social que les permita gritar su indignación y demostrar sus capacidades de productores de un hábitat para todas y todos. La diversidad de condiciones y contextos se ilustra con cinco casos de hábitat indignante en Argentina, Guatemala, Ghana, Chile y Estados Unidos. Hay muchas formas en que el estado y la sociedad ci$\mathrm{vil}^{4}$ intervienen para mejorar las condiciones de la vivienda en las barriadas y alcanzar la meta 7.11 de los objetivos de desarrollo del milenio (ODM). Un ejemplo de ello, en Caracas, muestra cómo pueden combinarse recursos y capacidades, junto con elementos de alta tecnología, para dignificar el hábitat de los que sobran. La última parte del artículo muestra dos ejemplos, en África del Sur y en Brasil, de cómo se organiza la sociedad civil para construir el hábitat de todas y todos a partir del derecho a la ciudad.

\section{El chabolismo, un tema de sociedad y territorio}

ONU-Hábitat (2003) define el chabolismo-slumbidonville — por la comodidad de la escritura, en adelante slums - como la situación de un hogar radicado en un asentamiento informal que representa a un grupo de individuos que viven bajo un mismo techo en un área urbana y que carecen de una o más de las siguientes condiciones: acceso a agua potable y a saneamiento, durabilidad de la vivienda, área suficiente para vivir y seguridad de la tenencia, o sea los principios del derecho a la vivienda adecuada.

La ventaja de esta definición es su enfoque de

\footnotetext{
${ }^{3}$ Empoderamiento: Proceso por el cual las personas fortalecen sus capacidades, confianza, visión y protagonismo como grupo social para impulsar cambios positivos de las situaciones que viven. La filosofía del empoderamiento tiene su origen en los enfoques de la educación popular, desarrollada a partir del trabajo en los años 60 de Paulo Freire, y de la participación ciudadana, presentes en el campo del desarrollo desde los años 70. Para más información,

<http://www.dicc.hegoa.ehu.es/listar/mostrar/86>

4 En este artículo, estado y sociedad civil se escriben en minúsculas, para así respetar el enlace entre estos dos actores de igual importancia.
}

derecho, que incluye la vivienda como parte de los derechos económicos, sociales y culturales (DESC). Sin embargo, en la era de los derechos colectivos emergentes ${ }^{5}$, la definición de ONUHábitat mantiene la base individual del derecho y puede llevar a estereotipos respecto de la pobreza urbana, dejando de lado las causas políticas, económicas, religiosas y culturales que crean y reproducen situaciones de exclusión y marginación.

Otra limitación de la tesis de ONU-Hábitat está en el uso de la palabra informal para caracterizar a los asentamientos slum. A partir de las discusiones sobre la informalidad que Hernando de Soto introdujo a fines de los años ochenta, en pleno apogeo del neoliberalismo, se entiende que un asentamiento informal está fuera de los marcos legales y normativos que rigen el territorio. Por lo tanto, la informalidad habitacional se define por estar al margen de las normas que rigen el tejido territorial y el uso del suelo, establecidas por las políticas públicas y el mercado inmobiliario, muy a pesar de los procesos socio-espaciales. Esta definición de informalidad y la correspondiente estrategia para superarla, que han alcanzado gran aceptación entre los gobiernos y las instituciones internacionales, centran la solución en la legalización de los terrenos, de manera que todos los habitantes del planeta puedan tener acceso al mercado financiero y entren al proyecto del neoliberalismo, del desarrollo personal en vez del empoderamiento social, de la reducción del rol del estado, de la privatización de todos los servicios y de la

\footnotetext{
${ }^{5 "}$ Los derechos humanos son resultado de un proceso inacabado y en permanente transformación. Emergen nuevos compromisos, necesidades y nuevos derechos. Aparece la toma de conciencia de las sociedades actuales que hacen visibles a pueblos o a nuevas identidades y grupos sociales, que hoy aparecen con voz a través de la emergencia de una sociedad civil internacional organizada, que exige el reconocimiento de nuevos derechos y la búsqueda de mecanismos para hacerlos efectivos para todos". Gloria Ramírez, Institut de Drets Humans de Catalunya. <http://www.idhc.org/esp/documents/CDHE/CDHE_Ramirez.p $\mathrm{df}>$
} 
mercantilización del bien común. Varios estudios del Centro de Estudios y Promoción del DesarroIlo, Desco, en el Perú han mostrado los límites de esta estrategia: un millón quinientos mil títulos de propiedad se han regularizado en el país en los dos últimos decenios; de todos los beneficiarios de esta política, tan sólo diez mil han llegado a obtener un crédito; también se ha observado que las comunidades beneficiadas han retrocedido en su capacidad organizativa después de llegar a la titulación de sus predios.

Si el slum es asunto de informalidad, surgen entonces preguntas sobre cómo se establecen los parámetros de la legalidad. Por un lado, las Naciones Unidas reconocen que, en el mundo de 2010 , el $33 \%$ de la población urbana vive en slums, en porcentajes que mucho varían entre países y continentes, cubriendo rangos que van del 1 al 90\% (Acioly, 2011). ¿A partir de qué variables se pueden comparar las condiciones habitacionales, por ejemplo, entre Sudán y Suecia, entre Haití y Hawai, entre China y Chile? Por otro lado, como lo señala Reese (2012), en América Latina se estima que el $75 \%$ de los tejidos urbanos no corresponden a las normas vigentes en cada país. ¿Qué construye la ciudad: la legalidad o los procesos de producción social?

Las respuestas son complejas y requieren mucho del equilibrio taoísta del ying-yang: en todo lo luminoso hay también algo oscuro; en lo luminoso y en la oscuridad, hay algo luminoso y algo oscuro. Si la historia muestra que "la seguridad física y la continuidad social fueron dos de las grandes contribuciones de la ciudad" (Mumford, 2011, concluyendo el punto "Simbiosis urbana y dominación"), veamos cómo la concentración de poder político y económico en la urbs ha creado distancias territoriales para separar el hábitat de los que sobran. Pienso en la ciudad de la Conquista en América Latina, que estableció el muy institucional pueblo de indios, fuera de la muralla, para realizar con mayor eficiencia el cobro de los tributos, aumentar el control y aculturación de la población sometida mediante la evangelización y disponer de concentraciones de mano de obra barata. Pienso en el origen y derivaciones del ghetto, larga historia urbana de barrios separados para el hábitat de determinados grupos étnicos o religiosos, en mayor o menor nivel de marginación o exclusión. Pienso en cómo hoy 'gueto' es término que se aplica para caracterizar el hábitat de los marginados y excluidos. Pienso en la historia bélica de este mundo y en los desplazamientos de refugiados que dejan sus lugares de origen para terminar asentados, en condiciones infrahumanas, en hábitats temporales donde tienden a perdurar en la marginalidad. Lewis Mumford (2011) nos dice que la historia de las ciudades aún no se ha escrito; tendremos que velar para que estos estudios incluyan la perspectiva de los que sobran, en proceso de convertirse en más indignados.

Sobre la exclusión social en la historia, Castel (2009, p. 245-256) analiza el universo estigmatizado de los marginales, explicando cómo la Escuela de Chicago en los años veinte del siglo pasado, abordó por primera vez el término 'marginal', asociándolo a la movilidad y a situaciones sociales inestables. La marginalidad —dice- no es pobreza, ya que, en la mayoría de los casos, el pobre está integrado. En cambio, el marginal es un extraño extranjero que la sociedad tiende a estigmatizar en las formas más frágiles de la vulnerabilidad popular, asociando miseria, crimen y asocialidad. La historia demuestra, sin embargo, que la marginalidad no siempre es irreversible. Castel se pregunta en "qué condiciones la marginalidad, estado frágil e inestable, pero a menudo también dinámico y movilizador, conduce a atolladeros (o el vuelco en la exclusión), permite formas de 'ingenio' individual (refiriéndose al Lazari- 
llo de Tormes), o es un factor de cambio social global (refiriéndose a la formación de la clase obrera)" Castel (2009, p. 256).

Es imposible responder a esta pregunta de forma perentoria. Sin embargo, desde la práctica, analizando las formas del hábitat en condiciones de marginación y de exclusión, surgen respuestas acordes a la diversidad de cada contexto y del proceso histórico de cada asentamiento. Todas y todos conocemos lazarillos en los slums, su astucia para sobrevivir, al límite de la dignidad y de la legalidad. Más complejo y, a la vez, indispensable resulta analizar las situaciones de cambio social donde las comunidades, las organizaciones, los movimientos logran hacerse oír y ser parte de procesos de cambio en sus condiciones de vida y de asentamiento.

Los habitantes, mujeres ${ }^{6}$ y hombres, sus capacidades para hacer prevalecer su voz, para defender sus derechos, para torear su camino entre las trampas del asistencialismo, la cooptación, el neocolonialismo o el negocio de la cooperación al desarrollo, y para ser partícipes de decisiones vinculantes, son indicadores que debemos descubrir y analizar para pensar la ciudad en función de los cambios sociales y no en función de la división del espacio urbano mediante la aplicación de estereotipos, como lo es slum. Esto lo aprendimos hace cuarenta años en la publicación "De invasores a invadidos" (Riofrío y Rodríguez, 1972).

En este sentido, veo en el Planet of Slums de Mike Davis (2006) un gran fresco dantesco, algo como el Planeta de los simios, que estigmatiza en la marginalidad y la exclusión a mil millones de personas que no tienen el derecho a vivir en un

\footnotetext{
${ }^{6}$ Desde la perspectiva de género, resulta obvio que las luchas por los derechos al hábitat son lideradas por las mujeres. Los múltiples roles productivos y reproductivos de la mujer en la familia, la comunidad y la sociedad, la acercan de forma especial a los temas de la vivienda, el barrio, la aldea, el territorio.
}

lugar en paz y dignidad. El libro de Davis ha sido acogido en el mundo intelectual progresista como el resultado de una tormenta violenta en contra de los gobiernos corruptos, de las intervenciones institucionales fracasadas, especialmente los programas de reajuste estructural impuestos por el Fondo Monetario Internacional que siguen consolidando las prácticas de élites para impedir el acceso de los pobres al buen vivir $^{7}$ de la ciudad. Como lo analiza Angotti (2006), en un aparente azote al neoliberalismo reinante, Davis, sin embargo, desacredita las opciones e iniciativas populares.

Una revisión del Planet of Slums sugiere elementos de análisis a través de los cuales se descubre que la obra de Davis se encuentra más cercana al neoliberalismo contra el cual aparentemente se yergue. La avalancha de información ahí compilada omite un dato esencial: el pensamiento y la voz de los habitantes, sus luchas y sus conquistas; eso sí, se explaya a lo largo de todo el libro sobre sus derrotas. El mismo uso reiterado de la palabra slums, con su clara connotación racial, lleva a justificar la erradicación de aquel hábitat que no se acomoda a los estándares normativos de las élites políticas y económicas (Pithouse, 2008).

Estos debates introducen dilemas y dudas en los intentos de comprender la complejidad de las causas y síntomas de los slums en tanto aditamentos malignos en territorios supuestamente integrados; su complejidad como espacios estigmatizados en relación con sus vecinos inmediatos, sea en dinámicas excluyentes o integradoras. La tragedia de tantos miles de personas en condicio-

\footnotetext{
7 Sumak kawsay en quechua expresa la idea de una vida no mejor, ni mejor que la de otros, ni en continuo desvivir por mejorarla, sino simplemente buena. Para mayor información, véase el artículo de José María Tolosa, "Sumak Kawsay, Suma Qamaña, Buen Vivir", en Rebelión. $<$ www.kaosenlared.net/noticia/sumak-kawsay-suma-qamanabuen-vivir>
} 
nes habitacionales indignantes se sostiene y se repite en el paradigma de acumulación de capital, en el contexto de un gran crecimiento de la población, de una economía más especulativa que productiva, de derroche de los recursos del planeta y de distribución desequilibrada e inequitativa de los bienes que favorece a las élites, sea en el norte o en el sur del planeta. Este paradigma conlleva la estigmatización de los pobres; va de la mano con el asistencialismo que pretende ir mejorando, de alguna forma, sus condiciones de vida y que de hecho perpetúa la precariedad de las situaciones del hábitat de gran parte de los sectores populares. En contraposición, emergen las oportunidades de cambio y de construcción de alternativas políticas, económicas, sociales y ambientales, en las cuales los habitantes de los slums, por sus luchas, conquistas y derrotas, puedan tener la posibilidad de reivindicar sus derechos y exigir la concreción, en su hábitat, de la justicia y la equidad.

\section{La diversidad de slums}

Mike Davis (2006), en su estudio sobre los slums, describe —en una visión apocalíptica - la realidad del hábitat urbano de los pobres, "el peor de los mundos". En el capítulo 2 analiza la predominancia de los slums (Davis, 2006, p. 23-52). Llega a estimar que hay más de doscientos mil slums en el mundo; un número que considero aleatorio, que no refleja la complejidad de la gran diversidad de condiciones y contextos sociales, políticos, económicos y geográficos de estos asentamientos. Al listar en su libro las mayores concentraciones de mega-slums, aparecen en una misma pincelada las grandes barriadas de Nezal en México, el Cono Sur de Lima, la Ciudad Bolívar en Bogotá, Pikine en Dakar, la ciudad de El Alto, el territorio militarmente sitiado de Gaza, los asentamientos de Kibera y Mathare en Nairobi o la Cité du
Soleil en Port-au-Prince, por citar los que, de alguna forma, conozco.

El hábitat de los que sobran debe ser analizado en detalle, asentamiento por asentamiento, uno a uno, en su contexto histórico y geográfico, para entender sus problemas, descubrir sus potencialidades, y empoderar sus organizaciones y alternativas de cambio hacia la integración del slum a la ciudad o al territorio.

A continuación, presento cinco casos de hábitat indignante, con cinco historias (escritas por distintas plumas), en cinco contextos y con perspectivas muy diversas de solución. Es verdad que, de los cinco ejemplos, tres vienen de América Latina. Éste es un sesgo mío; en este contexto latinoamericano he aprendido a analizar las realidades del hábitat a partir del reconocimiento de la diversidad, muy por encima del análisis de fenómenos abstractos, de estadísticas urbanas poco comparables y de visiones desesperadas sobre la condición de vida de los pobres.

\section{La Villa 31 en Buenos Aires ${ }^{8}$}

Cada día que pasa se consolida más el fenómeno identitario y de crecimiento de la Villa 31 en el barrio porteño de Retiro, desarrollada a ambos lados de la autopista Illia junto a las vías del ferrocarril San Martín en pleno centro de la ciudad. Ante la llegada imparable de nuevas familias migrantes nacionales o internacionales que se instalan cada día en la villa, la única opción es crecer en altura, debido a la imposibilidad de crecer en extensión. Lejos de las antiguas casas de lata y cartón que antes proliferaban, se levantan ahora de manera incontrolada torres irregulares y tambaleantes de hasta cinco plantas de hormigón armado y ladrillo, recursos materiales y humanos generados en el propio barrio, donde el trabajo no falta. Unas

\footnotetext{
8 Elaborado por la arquitecta Paula González Azcarate, a partir de Liernur (2008).
} 
70.000 personas de bajos ingresos residen en este exclusivo y estratégico lugar, donde el metro cuadrado puede valer hasta 4.000 euros. La or

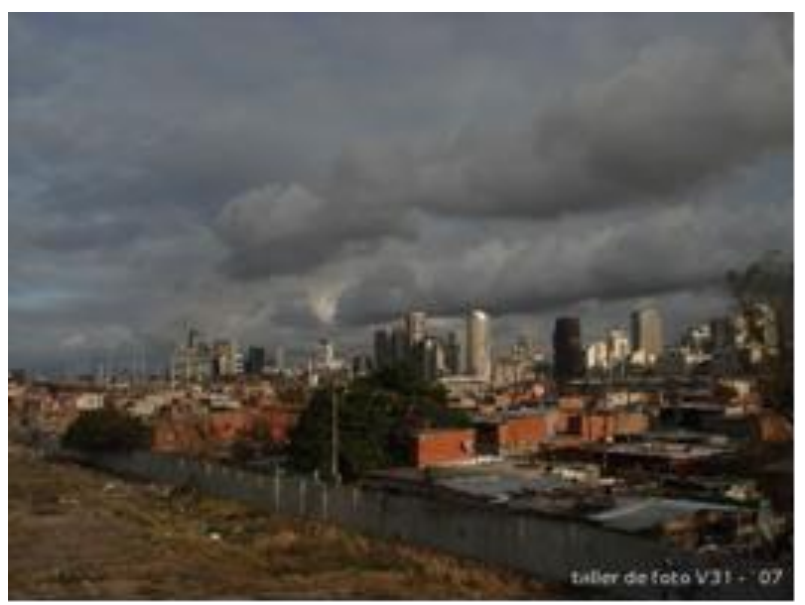

ganización social del barrio cultiva el sueño de lograr algún día la tenencia de la tierra.

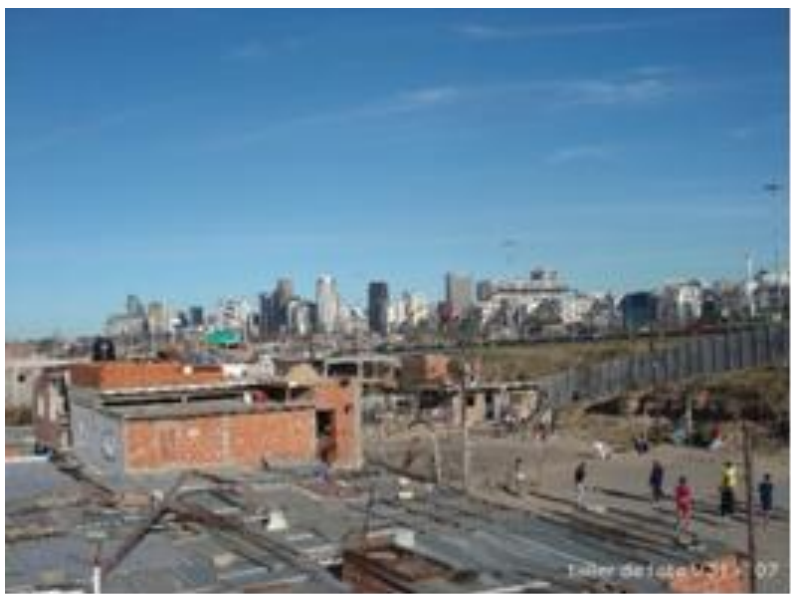

Figura 1. Villa 31, Buenos Aires (izqda y dcha). Fuente: archivo del Taller de Fotografía de la Villa 31-31bis, Pablo Vitale, coordinador (2011).

Este asentamiento nació en los años treinta como una villa de emergencia, llamada en sus orígenes Villa Esperanza. Se trata de un lugar arraigado al lugar. Con figuras tan veneradas como el asesinado sacerdote Mújica y el difunto Pichi Mesegeier, sj. ${ }^{9}$, esta población se mantiene consolidando cada vez más su estructura, firme frente a las políticas de los diferentes gobiernos y dictaduras. Otrora amenazada y víctima de erradicación, con el devenir de las diferentes políticas públicas influenciadas por acciones internacionales y, dado el incesante desarrollo y organización social de estos asentamientos informales y su aparición en los medios de comunicación, en estos días prevalece la idea de su radicación y mejora.

Hoy, ante las protestas y reclamaciones de la población por el incumplimiento del gobierno local de ejecutar las mejoras prometidas en momentos de campaña electoral, la respuesta institucional no resuelve; y en medio de improductivos debates, la respuesta se pierde en la evasión de responsabilidades entre los diferentes niveles de la administración pública. Ideas no faltan, pero eso 9 Para más información, ver en <http://www.hic-
net.org/pichi/index.php> no es suficiente. El gobierno de la nación con pequeñas intervenciones populistas, por un lado; por otro, el gobierno local con diferentes soluciones en vano, como transformar el área en un gran espacio verde; o la última alternativa, llevar a cabo un proyecto de regeneración urbana que pudiera llegar a incorporar el conjunto como una parada más en las rutas turísticas de la ciudad. Al igual que en otras ciudades latinoamericanas, propone rehabilitar el espacio público, como ilustra el plan maestro elaborado por la Facultad de Arquitectura de la Universidad de Buenos Aires para la Villa 31 y 31 bis, proyectado quizá sin el suficiente debate y participación ciudadana que el enclave merecía. Proyecto urbano que plantea recuperar la zona en su conjunto atendiendo no solo a las viviendas, sino a los equipamientos e infraestructuras y servicios necesarios, integrando lo construido por los vecinos a lo largo de su historia.

Mientras, ante la ineficacia en dar soluciones, persiste la informalidad del asentamiento, cuyos costos económicos y sociales son muy elevados. Conexiones clandestinas y acciones asistencialistas del gobierno para resolver la provisión de ser- 
vicios básicos son soluciones provisorias que se alargan en el tiempo. Insalubridad, precariedad y miseria de un grupo humano segregado y condenado.

La Villa 31 es un asentamiento sui generis que se explica tan solo en el contexto de Buenos Aires y en la historia de Argentina. Ha sido erradicada, re-tomada, vilipendiada, cooptada, desechada y negociada. Una hipótesis sobre la relación de este asentamiento con su entorno de ciudad bella y rica, y a la vez llena de conflictos y ambigüedades, es que la Villa 31, remozada y, de alguna forma, legalizada, sea determinada por el negocio de la ciudad, por su vocación turística. Que se la convierta en una atracción patrimonial, como ya pasó con la Boca en el sur de esta misma Buenos Aires, como se ha dado con el Raval en Barcelona, con el barrio de San Luis-Alameda en Sevilla; y como ocurre también, en un proceso similar, con las favelas de Río de Janeiro ante los meganegocios de los mega-eventos de la Copa Mundial y de las Olimpiadas en Río de Janeiro.

\section{La Limonada, Zona 5, Ciudad de Guatemala $^{10}$}

Fue en 1959 cuando llegaron los primeros pobladores a La Limonada, uno de los numerosos asentamientos precarios existentes en la ciudad de Guatemala, de los más grandes de América Latina. Está en pleno centro, a pocas cuadras de la Municipalidad y del Palacio de Gobierno. Topográficamente, está colgado de las laderas y amontonado en el fondo del contaminado río Las Vacas, uno de los varios barrancos que surcan de sur a norte la meseta de la ciudad de Guatemala. Jamás ha sido planificada y sus habitantes no se consideran parte de la ciudad, pero viven de ella; en la mañana, suben y entran a la ciudad, multiplicando chambitas y servicios tan informales co-

\footnotetext{
10 Elaborado por la arquitecta Paula González Azcárate, a partir de Valladares (2003).
}

mo su asentamiento.

La Limonada es el producto del trabajo de cada una de las familias y de centenares de proyectos aislados que, de forma cíclica, el alcalde de turno, las iglesias fundamentalistas y cantidad de organizaciones sin fin de lucro, van reproduciendo para el saneamiento, las escaleras, la educación, el templo, la acupuntura, las cooperativas, la salud, el ahorro, el abasto; de vez en cuando, la organización local.

La Limonada está dividida en sectores que se caracterizan más por las diferencias de liderazgo que por la distribución territorial. Al extremo de que, en un mismo callejón, una familia pertenece a un sector y su vecino inmediato, a otro.

Las casas eran de cartón y madera. Hoy en día son de hormigón y lámina de zinc; hay hasta casas prefabricadas que emergen en un delicado equilibrio, adaptándose a la vaguada. El río que lo atraviesa, lleno de basura y causante de numerosas inundaciones y epidemias, serpentea entre las viviendas, a las que se accede a través de estrechos caminos, en ocasiones asfaltados. Las redes de servicios básicos también han llegado: luz, agua, teléfono, e incluso internet.

Levantado en un territorio sin normas, bajo la ley del más fuerte, ignorado y marginado por los gobiernos de turno, el territorio ha quedado completamente colapsado, dando lugar a una verdadera pugna por controlar el mercado del suelo. Cerca de 60.000 habitantes viven ahora en La Limonada.

También de forma cíclica, hay amenazas de desalojo. Pero nadie las cree. No hay violencia que saque a la gente de La Limonada. Más bien, la violencia es intramuros, aprovechada por los externos, sean de las ONG, las maras o los narcos. El porvenir de La Limonada es tan incierto como lo es el centro de la Ciudad de Guatemala, o todo el país, que solo ha vivido en paz y democracia entre 1951 y 1955. 
A la inversa de la hipótesis formulada para la Villa 31, el contexto histórico de Guatemala predetermina una trayectoria de precariedad y procesos sostenidos de deterioro para La Limonada y también para su entorno de centro de ciudad. Muchos años de dictaduras y de guerras inciviles, la inestabilidad institucional, la cultura de la violencia, el apartheid en contra de los mayas, las llamaradas de las maras, la democracia mantenida en el discurso y sin práctica ciudadana, son parámetros que marcan la calidad de vida en La Limonada, al igual que en otros asentamientos colgados en las vertientes de otros barrancos, como El Incienso, y en todos los barrios históricos y populares de la Ciudad de Guatemala. Las élites viven moviéndose, solo en carro, entre la casa enrejada en barrios cerrados, los malls y las oficinas dotadas de altos sistemas de seguridad, la finca y el aeropuerto.

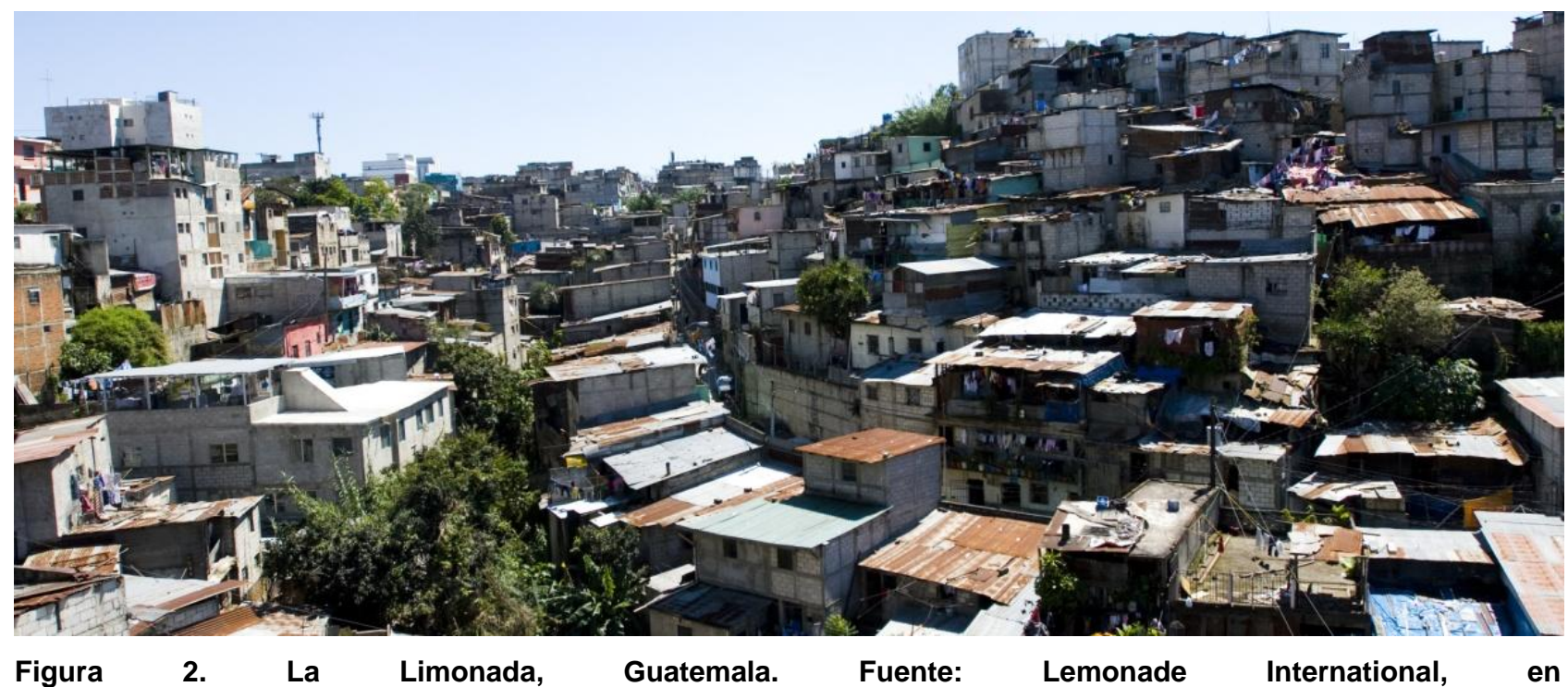
<http://www.lemonadeinternational.org/about-lemonade-international-2/la-limonada/.>

Los sectores medios y bajos desarrollan otra cultura de la reja y viven con tanto miedo como las élites. Me pregunto si La Limonada —pese a la inseguridad de la tenencia, la pestilencia de la cloaca del río Las Vacas, la fragilidad geomorfológica de estos barrancos, cada invierno los deslaves provocados por las lluvias torrenciales, el laberinto de callejuelas tortuosas, el hacinamiento de familias numerosas en lotes de siete metros cuadrados, el cansancio de subir las escaleras para llegar a la ciudad- puede representar una isla de solidaridad renaciente en esta Guatemala entrañable ${ }^{11}$.

\footnotetext{
11 Hipótesis formulada a partir de mis experiencias en La Limonada, donde trabajé como parte de la Central de Servicios Urbanos del Instituto para el Desarrollo Económico Social de América Central (IDESAC), en los años de la guerra, entre 1976 y 1991, mano a mano con un grupo de jóvenes líderes
}

\section{Old Fadama en Acra ${ }^{12}$}

Identificada como la mayor barriada de Acra, en Old Fadama viven más de 60.000 personas en una extensión de unas 146 hectáreas. Recibe la llegada constante de inmigrantes agricultores venidos del norte del país huyendo de la sequía, y está conformada por una comunidad de personas de diferentes tribus, de lenguas y religiones diversas, que conviven en paz en un espacio dinámico, unidas por el temor constante a ser desalojadas. Este asentamiento informal tiene una localización extremadamente estratégica; se encuentra

locales, mujeres que alcanzaron títulos de educación superior, consiguieron empleo en instituciones muy formales, siguen viviendo en La Limonada y mantienen su compromiso de servicio a su comunidad. 
situado al sur de Abose-Okai Road, cercano a la laguna Korle y en las inmediaciones del mercado Agbogbloshi, al noreste del Central Business District (CBD). Casas de madera y chapa, carentes de abastecimiento de agua potable y servicios sanitarios adecuados, se amontonan sin orden en lo que fue un antiguo bosque, hoy una de las áreas más densas de la ciudad, que crece cada día fuera de cualquier planificación y urbanización. El comercio informal de chatarra y desechos electrónicos y otros negocios, así como burdeles, son el modo de vida de muchos de sus pobladores. Víctima de numerosas inundaciones, incendios y epidemias, este asentamiento ha sido, además, constantemente estigmatizado por las autoridades y medios de comunicación, con el objetivo de rebajar el estatus social de sus habitantes y justificar así un posible desalojo.

La municipalidad de Acra lleva amenazando a los habitantes de estas tierras con la expulsión desde 2002, ajena cualquier tipo de responsabilidad social para con sus ciudadanos. Preocupada por un proyecto de recuperación ecológica de la zona de la laguna Korle, por un lado, y por la regeneración del barrio $\mathrm{CBD}$, por otro, según el modelo neoliberal de planificación urbana, el trabajo con esta comunidad para garantizarle una vivienda digna, queda por completo fuera de sus planes.

Pero la realidad de Old Fadama no es tan simple y la resignación en ella no es tan grande. Por el contrario se trata de un asentamiento con un nivel de organización interno muy elevado social y políticamente. En este caso, es encomiable la importancia que tuvo en el éxito de la actual radicación del barrio el contacto y apoyo con las redes globales internacionales que trabajan por los derechos de los marginados urbanos en temas de resistencia y lucha por la tenencia de la tierra. Este proceso ha fortalecido, en las zonas urbanas de

12 Elaborado por la arquitecta Paula González Azcárate, a partir de Afenah (2011).
Ghana, la capacidad y los recursos de los pobres en temas de participación ciudadana para una planificación urbana más democrática, así como la reivindicación de una distribución equitativa de las redes y equipamientos. Gracias al trabajo que se hizo con organizaciones internacionales, se desarrollaron las fortalezas y oportunidades que mejoraron la organización social, política y económica de la comunidad, con el objetivo de empoderarla en los temas del derecho a la ciudad.

De este proceso nació un centro de apoyo y la Federación de los Pobres Urbanos ${ }^{13}$ de Ghana que, además de la asistencia técnica y trabajos de capacitación, empoderamiento e investigación con la comunidad, representaron a la comunidad en diferentes diálogos con el gobierno. Estos encuentros han tenido grandes éxitos y retrocesos, pero el proceso está todavía abierto en un escenario en que la capacidad de respuesta colectiva es cada vez más firme y respaldada por colaboraciones transnacionales que amplían este diálogo.

Old Fadama, esta gran mancha de viviendas precarias que concentra el $3 \%$ de la población de la capital de Ghana, nos lleva a la dimensión africana del problema candente de los slums. En Ghana, la historia actual de migración campo-ciudad recuerda fenómenos similares ocurridos en América Latina en décadas anteriores: en ambos contextos, las políticas urbanas, si es que existentes, han reproducido los patrones del colonialismo, con su multiplicación de los acaparamientos de tierras y desalojos masivos. Old Fadama también nos lleva a esta otra forma de analizar el problema de los slums, aquella que lo hace desde la perspectiva de sus habitantes, de sus victorias y derrotas.

La aparición, desarrollo y transformación del hábi-

${ }^{13}$ En inglés, Federation of Urban Poor, que lleva a la sigla FED-UP [harto/a], que expresa la indignación. Estas federaciones existen en varios países del África Subsahariana anglófona. 
tat de los que sobran exige miradas capaces de analizar nuevas formas de producción de situaciones de marginación y exclusión. El próximo caso, las Villas Serviu en Chile, ilustra cómo, en nombre de una política social de vivienda, el estado y el sector privado desarrollan una producción masiva de viviendas de muy bajo estándar, reduciendo el déficit habitacional acumulado,

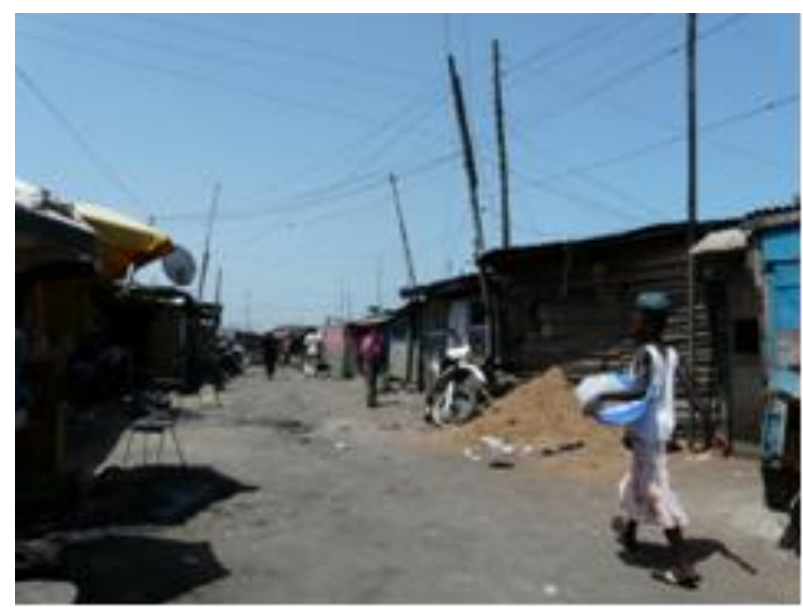

cumpliendo con todos los requisitos de la ordenanza de construcción y urbanismo, entregando las casas llave-en-mano y en propiedad, con un alto porcentaje de subsidio, involucrando también al mercado financiero con la otorgación de créditos más allá de las capacidades de endeudamiento de los beneficiarios. El producto viene a ser una nueva forma de slum.

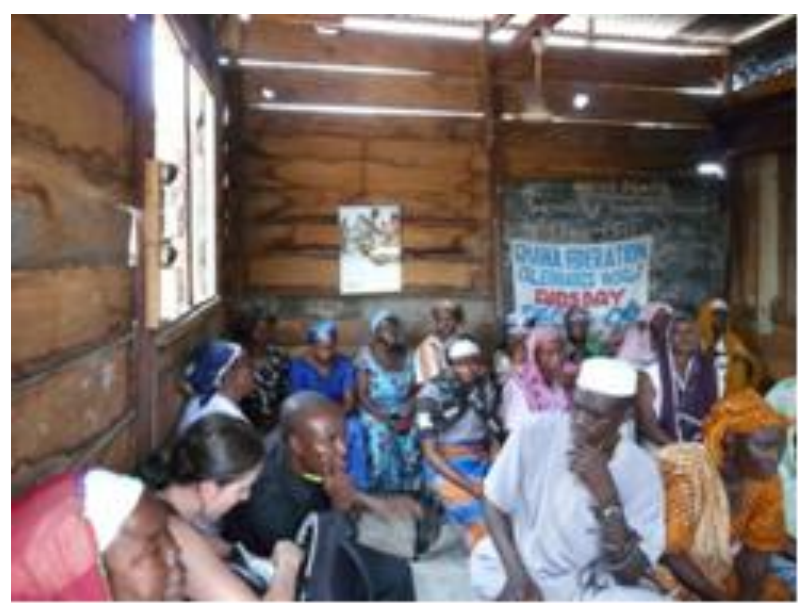

Figura 3. Old Fadama, Ghana, Africa (izqda y dcha). Fuente: archivo personal.

\section{Las Villas Serviu en Santiago ${ }^{14}$}

El subsidio habitacional, o el mecanismo de financiamiento de la vivienda de bajo estándar en Chile, ha dado techo a los pobres. En un país de 15 millones de habitantes, entre 1985 y el año 2000 se han construido 600 mil viviendas de valor nominal inferior a 10 mil euros.

Este subsidio, establecido en el marco del reajuste estructural inspirado en los Chicago Boys, desarrollado a punta de fusil en la dictadura y consolidado en la democracia, ha estabilizado al sector de la construcción en el proyecto imperante de crecimiento económico.

Los productos de mala calidad de esta política de financiamiento de vivienda social se concentran en alta densidad en manchones homogéneos de pobreza en la trama urbana de todas las ciudades de Chile y muy especialmente en Santiago. Aquí,

14 Elaboración propia, a partir de Rodríguez y Sugranyes (2005). Serviu, Servicio Regional de Vivienda y Urbanización, es la instancia responsable de la ejecución de los programas del Ministerio de Vivienda y Urbanismo (Minvu). por ejemplo, el manchón La Cisterna cubre 350 hectáreas. Se extiende transversalmente entre las comunas de La Florida, La Pintana, La Granja y San Ramón. Son 82 proyectos con un total de 34 mil viviendas, construidas entre tres empresas constructoras. La explicación de esta expansión territorial está en el sistema de licitación de los proyectos hasta mediados de los años noventa: los constructores concursaban al subsidio aportando el terreno; de esta manera, definían la localización de la vivienda social en función de la rentabilidad de sus terrenos en áreas de poco interés inmobiliario en la periferia de la ciudad.

Esta nueva forma de guetos urbanos representa la mayor precariedad habitacional en Chile. Las estadísticas de Naciones Unidas a 2010 atribuyen a Chile un $0,9 \%$ de asentamientos precarios, contra un promedio que va del 10 al $50 \%$ en el resto de América Latina. Los parámetros de análisis de la precariedad habitacional urbana no incluyen el stock de vivienda social.

Los slums de vivienda social representan un nue- 
vo desafío para las políticas habitacionales y urbanas. Exigen una reinversión del estado y de la sociedad que empodere a los habitantes hacia una apropiación del espacio y desarrolle alternativas para una lenta reinserción de estos guetos en la trama urbana.

Entre 2005 y 2010, el gobierno diseñó e implementó una intervención de mejoras del espacio público en las Villas Serviu. El Programa Quiero Mi Barrio movilizó recursos fiscales para planificar y desarrollar proyectos participativos en 200 villas, una apuesta muy ambiciosa para un periodo bastante corto. Los resultados muestran más avances en el despertar de capacidades de organización local que en mejoras tangibles de la calidad física del espacio público en los barrios intervenidos.

La política de financiamiento de la construcción aplicada en Chile demuestra que es posible dar respuesta masiva a la demanda de los sin techo. Demuestra también que la producción de grandes conjuntos de viviendas de bajo estándar, basada únicamente sobre criterios de lucro de unas pocas empresas, sin intervención del estado en materia de política urbana ni reservas de suelo y sin la participación de los pobladores, crea nuevos problemas de marginación y exclusión. Lo mismo hemos visto en muchas partes en el mundo, por ejemplo con los HLM en Francia, pero en el caso de Chile, y del subsidio habitacional en otros países de América Latina, presenta serias trabas adicionales, puesto que la vivienda es entregada en propiedad.

El subsidio habitacional chileno es un modelo que los demás países de América Latina están copiando. En la Ciudad de México, por ejemplo, las extensiones de viviendas producidas en serie con apoyo estatal de subsidios son manchas uniformes de hasta 50.000 unidades. Son barrios amorfos, alejados de los centros de trabajo y de servicios. Su destino poco digno es ir sumándose a la nomenclatura del hábitat de los que sobran.

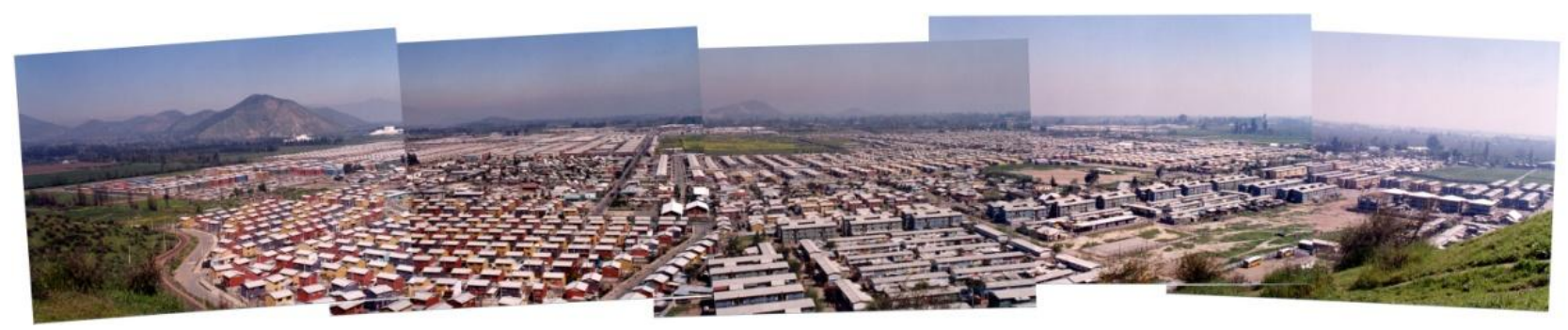

Figura 4. Villa Serviu, Puente Alto, Santiago de Chile. Fuente: archivo personal (2001).

Los problemas de los barrios de vivienda social son universales y golpean también una ciudad como Sevilla, con su Polígono Sur, donde las intervenciones de rehabilitación siguen trayectorias similares: mejoran las viviendas, pero sin abordar las claves del espacio público para facilitar procesos de re-apropiación del barrio por el conjunto de sus habitantes.

\section{Los slums de Detroit ${ }^{15}$}

El declive de Detroit se inscribe en la historia de las ciudades posindustriales en Norteamérica. La gran influencia de la industria automotriz y del sector manufacturero fue indiscutible desde los años treinta del siglo pasado, hasta que la automatización de la producción puso fin a los años de gloria del denominado cinturón de óxido -la

\footnotetext{
${ }^{15}$ Elaborado a partir de une entrevista con Catalina Ponce de León, canadiense de la región de Los Lagos, colaboradora del Secretariado General de HIC.
} 
región que se extiende al oeste de Nueva York hacia los estados de Ohio, Michigan e Indiana-, donde se daban las condiciones óptimas de producción, entre la geografía de los lagos, la energía de las cataratas y el gran contingente de asalariados inmigrados.

El declive industrial ha reducido el $50 \%$ de la población de Detroit en los últimos cincuenta años. Es más, se ha visto una polarización socioeconómica y racial de la ciudad. En 1990, los afrodescendientes componían un $76 \%$ de la población del centro de Detroit, mientras que solo llegaba al $6 \%$ en la residente en la periferia. Sin embargo, los suburbios siguen siendo unos de los más prósperos del país. Aunque en 2000 la pobreza llegara al $32 \%$ en el centro, era de tan solo $6 \%$ en la zona metropolitana. Pese a las dificultades que vive la ciudad de Detroit, los suburbios siguen siendo áreas de altos ingresos, 13\% más que el promedio nacional. El análisis de ciudades posindustriales sugiere que, hoy en día, las crisis económicas y sociales de los centros urbanos son una consecuencia de la pérdida de empleos, discriminación racial y segregación de la vivienda que caracterizaron el periodo entre los años cuarenta y sesenta.
Como en las demás ciudades de este sector industrial de Estados Unido, la trama urbana de Detroit se centra en su downtown, con los mercados financieros, la administración pública y las áreas de servicios; sigue una extensión de barrios residenciales, las llamadas war houses, alrededor de las plantas automotrices y manufactureras; y se pierde en una vasta periferia sprawl donde viven los sectores más ricos.

Ahora, Detroit está en crisis y su hemorragia laboral y poblacional es evidente para cualquiera que lo visite: en el centro de la ciudad, está a la vista el abandono de edificios enormes, más antiguos y más recientes; un viernes por la tarde parece un desierto. Se salvan dos bolsones de vida, uno en torno a los restaurantes de Mexican Town, debajo de los enlaces de autopistas del puente frente al centro y la atracción turística de los casinos de Greek Town. Los barrios de los obreros muestran casas abandonadas y en estado de deterioro progresivo; al frente de estas viviendas, se mantienen anuncios de venta; se han visto pancartas declarando el valor de la venta en un dólar. Las antiguas plantas, también abandonadas, son vertederos nauseabundos. A estos distintos espacios muertos y podridos, los locales los llaman slums.
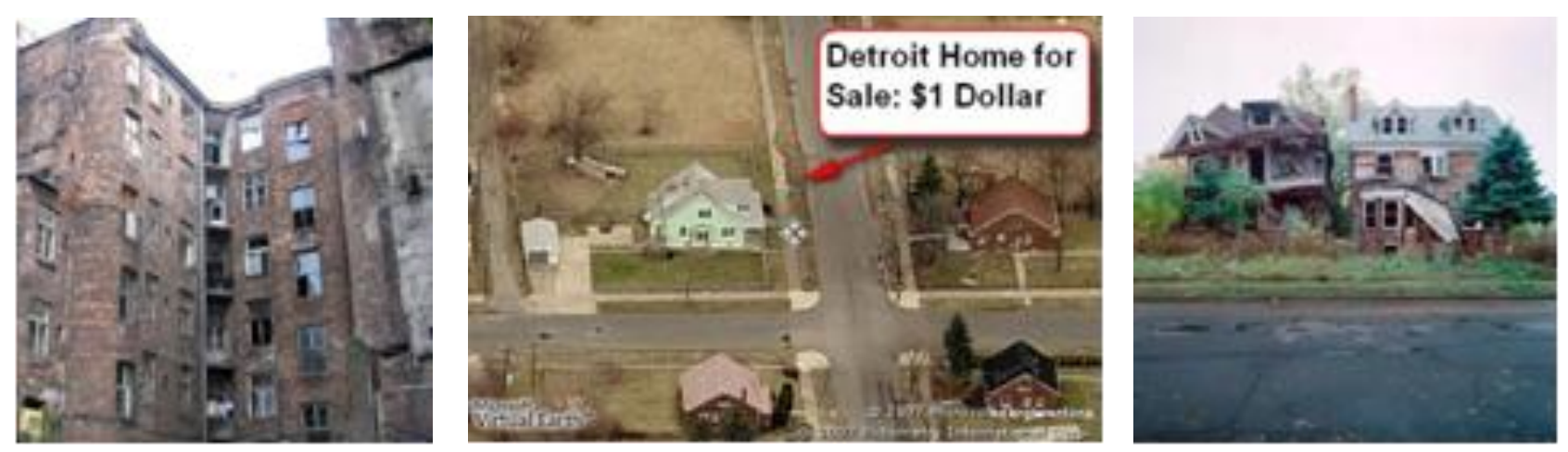

Figura 5. Edificio en Detroit (izqda). Casa por un dólar (centro). Casas en Detroit (dcha). Fuente: Izqda: <http://drpinna.com/empty-city-streets-now-detroit-17347>. Centro: <http://www.zillow.com/blog/2008-08-14/1will-buy-you-a-home-in-detroit/> Dcha: <http://www.victoryinstitute.net/blogs/utb/2011/02/who-won-world-warii $>$.

El desenlace de las shrinking cities, o ciudades en proceso de encogimiento, como lo vemos en Detroit, se repite en muchas partes del hemisferio norte. Las reacciones son distintas y variadas. Los movimientos sociales de Estados Unidos unieron sus reclamos en solidaridad con Detroit 
en un gran foro social en 2010. Diecinueve ciudades de la región posindustrial del Ruhr, en Alemania, se han unido en un plan de contingencia de desarrollo urbano. En términos de análisis, habrá que dar seguimiento a estas nuevas situaciones y lo que puedan representar en términos de marginación y exclusión habitacional.

Relacionado a los tiempos de crisis del sistema financiero y de la mercantilización del hábitat, no perdamos de vista otras formas de marginación habitacional dadas por la venta de créditos hipotecarios con exigencias rebajadas, en la espiral de las burbujas inmobiliarias. Sea en el cinturón de óxido de los Estados Unidos, en España y en Chile también, el remate de viviendas deja centenares de miles de familias en la calle, en otra expresión de marginación habitacional.

Estos ejemplos dispersos en la historia y la geografía sugieren algunas ideas globales: El hábitat de los sectores marginados del poder y de los grandes negocios muestra una infinidad de diferentes condiciones indignas, sea en la seguridad de la tenencia, en la habitabilidad o en la localización. Sin embargo, los habitantes, mujeres y hombres, excluidos del buen vivir en la ciudad, demuestran capacidades de resistencia y lentos procesos de mejoras progresivas.

\section{El intervencionismo}

"La caridad comienza donde termina la justicia." Alberto Hurtado, SJ, La Práctica de la justicia, (1947). Según Castel (2009, p. 247), "entre el ejercicio de la caridad y la represión, se da un gran despliegue de políticas de asistencia y la correspondiente criminalización..." de los marginados que se atreven a demostrar su indignación. Las intervenciones del estado y de múltiples instancias de la sociedad para mejorar las condiciones de vida en los asentamientos precarios son innumerables; en el mejor de los casos, suelen priorizar la regularización de la tenencia de la tierra, el saneamiento y el mejoramiento de la vivienda y de servicios en el barrio; en el peor de los casos, aplican la erradicación.

La era de los desalojos masivos parece haber pasado a la historia en América Latina. Sin embargo, esta nefasta práctica de poder y castigo, frente a la cual el intendente de Buenos Aires en los años ochenta alguna vez adujo que "la ciudad es de quien se la merece" — frase con que intentaba justificar la acción de la topadora en las villas (Oszlack 1991) —, hoy sigue condenando a centenares de miles de pobladores en ciudades del África Subsahariana.

El séptimo objetivo de desarrollo del milenio, ODM, que apunta al sustento del medioambiente, tiene un indicador, el número 11 , relacionado a las condiciones del hábitat. Propone que para el año 2020 se haya logrado mejoras significativas en las condiciones de vida de, por lo menos, cien millones de habitantes de slums. Este indicador es muy relativo, ya que, si bien entre 1990 y 2010 la tasa de personas residentes en slums bajó del 46 al 33\%, la estimación del número de personas que viven en asentamientos precarios pasó de 650 a 850 millones, tendencia que se aprecia irá en aumento en los próximos años, hasta llegar a los mil millones el año 2020 (Acioly, 2011). De todas maneras, la abstracción de estos números y objetivos no resuelve el problema del hábitat de los que sobran, a menos que el tono de voz de los indignados suba.

El monitoreo del cumplimiento del objetivo 7.11 de los ODM está regido por las bases del derecho a la vivienda, con énfasis en los indicadores de acceso a agua potable y saneamiento, de durabilidad de la vivienda, de la existencia de un área suficiente para vivir y de seguridad de la tenencia. Este monitoreo se lleva a cabo en 360 ciudades a través del programa Urban World, de ONUHábitat. Producto de las dificultades que enfrentan los gobiernos para llevar a cabo este complejo ejercicio, algunos países miembros del Consejo 
de ONU-Hábitat están retirando el indicador de seguridad de la tenencia, variable medular cuya comprensión se hace problemática al ponerse en juego su sentido como 'derecho de posesión de la tierra', frente a su dimensión formal y legal de 'título registrado'. Bien sabemos que esta variable es determinante para que toda mujer y hombre pueda tener el derecho a un lugar donde vivir en paz y dignidad; de ahí la duda de trabajar el tema de los slums a partir de este monitoreo (Acioly, 2011).

Para el alcance de este objetivo, el programa Cities without Slums, o ciudades sin chabolas, de ONU-Hábitat, propone a los gobiernos un conjunto de medidas para la consolidación del sector de la vivienda, la planificación urbana, las oportunidades de empleo, con lo que busca reducir el número de los asentamientos informales con prácticas muy similares a las ensayadas y ampliamente difundidas por el subsidio habitacional chileno y la doctrina del Housing: Enabling Market to Work del Banco Mundial. Me surgen dudas ante esta propuesta programática: se relacionan con el nombre del programa, por las connotaciones discriminadoras de la palabra slum, y su peligroso slogan, al estilo de tolerancia cero, ambos aspectos que a menudo llevan a justificar la erradicación indignante de estos asentamientos precarios. En 1970, los países ricos se comprometieron a contribuir cada año con el $0.7 \%$ del ingreso nacional bruto (INB) para la cooperación al desarroIlo; más tarde, en el marco de los ODM, el acuerdo se centró en $0,56 \%$ del INB para la reducción de la pobreza y del hambre en el mundo a 2010; luego esta tasa subió a 0.7\% para el cumplimiento de las metas a 2015. Sin embargo, muchos estudios especializados dan a entender que este objetivo no se va a alcanzar. A mi entender, la era de la "cooperación al desarrollo", tal como la vivimos entre los años 60 y 90, está en quiebra: la solidaridad internacional también se ha mercanti- lizado y, muchas veces, confunde cooperación con asistencialismo.

Las alternativas de mejoramiento de los asentamientos humanos, más allá de los fracasos de la cooperación oficial, se centran en la producción y gestión social del hábitat. Este concepto, desarrollado en América Latina desde los años setenta y ampliamente difundido por la Coalición Internacional del Hábitat (HIC, por su sigla en inglés), se explica en procesos de organización colectivos que buscan mejorar el hábitat a partir de sus habitantes, combinando recursos y capacidades de actores públicos y sociales, para trabajar los temas de la vivienda y de los barrios, sin fines de lucro. En el mundo entero, hay organizaciones de la sociedad civil $^{16}$ que trabajan codo a codo con los habitantes para mejorar las condiciones de la vivienda y de los barrios precarios. Entre ellas, cabe mencionar: Selavip ${ }^{17}$, que desde los años setenta colabora en América Latina, Asia y África en intervenciones mínimas para potenciar el inicio del proceso habitacional de los pobladores; de la mano con el Servicio Jesuita a Refugiados (JRS, por su sigla en inglés) ${ }^{18}$, que atiende los temas habitacionales en los campos de refugiados; distintas instancias autónomas de Enda-Tiers Mon$\mathrm{de}^{19}$, también desde los setenta, y especialmente en África del Oeste, sigue desarrollando tecnología para el saneamiento de barrios, con particular dedicación al análisis de los efectos del cambio climático en los barrios; Hábitat para la Humanidad $(\mathrm{HpH})^{20}$, heredera del Cuerpo de Paz, que

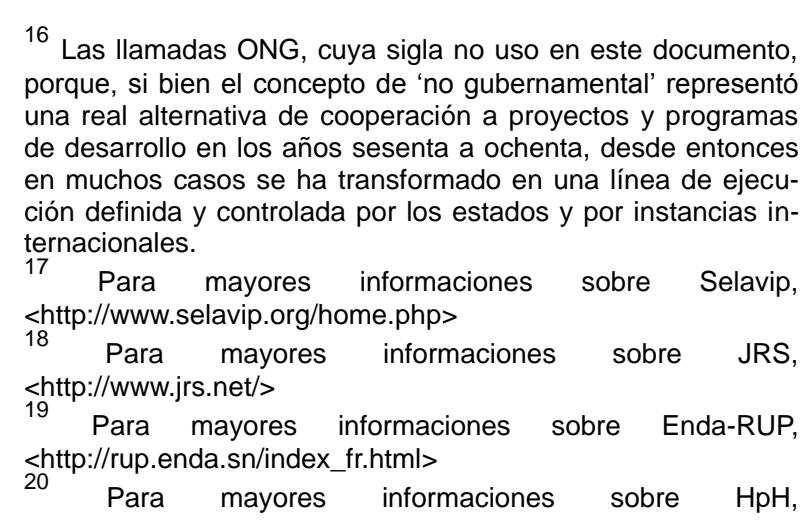


trabaja el tema de la vivienda y se está iniciando en los de mejoramiento de barrios en América Latina, Asia y África; Slum Dwellers International $(\mathrm{SDI})^{21}$, desde los años noventa, ha elaborado una metodología de radicación de barrios precarios de Asia y África a partir del ahorro comunitario; y Arquitectos sin Fronteras (AsF) ${ }^{22}$, una versión europea, con proyectos en África y América Latina. $Y$ una especial mención a organizaciones que, en América Latina, lograron incidir en políticas públicas de mejoramiento de barrios de su país, como Casa y Ciudad-Cenvi-Copevi-FosoviHIC-AL en México, Fundasal en El Salvador, Fuprovi en Costa Rica, Fedevienda en Colombia, FUCVAM en Uruguay, Madre Tierra y Fundación Vivienda y Comunidad en Argentina, o Desco en el Perú.

Elegí el caso presentado a continuación porque, entre los que conozco, éste cruza intervenciones complementarias, que contemplan aspectos como el empoderamiento de la organización local en un largo proceso de capacitación y pleno respeto a los tiempos y capacidades de los pobladores; un emprendimiento colectivo de producción social del hábitat; un complejo entramado de negociaciones con entidades públicas y privadas; muchas peleas entre los actores involucrados, la incidencia en medidas de política de prevención de riesgos; y la aplicación de sistemas constructivos high tech adaptados a las exigencias de una ayuda mutua eficiente y rápida (un ejemplo de "tecnología dura, pero con ternura", como se mencionaba en el proyecto MejorHab de CYTED, 1998).

\section{El Catuche en Caracas $^{23}$}

Este asentamiento, en pleno centro de la ciudad, tiene un origen y una morfología similar a $\mathrm{La} \mathrm{Li-}$

$<$ http://www.habitat.org/>

21 Para mayores informaciones sobre SDI, $<$ http://www.sdinet.org/>

22 Para mayores informaciones sobre AsF Internacional, $<$ http://asfes.org/sobre-ast/asf-internacional>

23 Elaboración propia. monada de Guatemala: un barranco, ocupado desde los años cincuenta; un río convertido en cloaca y condiciones infrahumanas del hábitat. Sin embargo, su historia ha cambiado de rumbo. Una escuela de Fe y Alegría ${ }^{24}$ se instaló allí en los años ochenta y empezó un lento proceso de empoderamiento de la comunidad. Éste se tradujo, primero, en muchos pequeños proyectos de mejoramiento y en 1993 llevó a la formalización del Consorcio Catuche, una asociación civil de los pobladores locales, con asesores técnicos y capacidad de negociación ante el estado.

En un proceso de producción social del hábitat y transformación del barrio, el Consorcio, con financiamiento propio, del estado y de institucionales locales, logró desarrollar un sistema de autocenso, estudios hidrológicos y de suelos, un plan de saneamiento ambiental y la construcción de viviendas de sustitución (pasando de la chabola a departamentos en altura; véase ficha más abajo). Las obras físicas realizadas por el Consorcio Catuche tienen enfoques técnicos: la prevención y control de riesgos geológicos; obras correctivas de riesgos de deslizamiento de tierras; la creación de vías de acceso, vehiculares y peatonales; el saneamiento de quebradas para el control de riesgos de desbordamiento e inundaciones; obras de servicios públicos y la recuperación de espacios públicos, con su equipamiento.

La construcción de las viviendas en altura se hizo con elementos prefabricados de acero-concreto livianos, de 5 centímetros de espesor, de no más de 103 kilos cada pieza, para la conformación de estructuras basadas en paredes portantes en dos direcciones.

La tormenta que cayó sobre Caracas para la $\mathrm{Na}$ vidad de 1999 causó muchos estragos en el Catuche: muertes, desbordamientos, ruptura de varios pilares del edificio de viviendas. El proceso

\footnotetext{
24 Programa educacional latinoamericano de la Compañía de Jesús.
} 
de reconstrucción logró consolidar el proceso de con el plan de las viviendas de sustitución. organización, reparar el edificio dañado y seguir
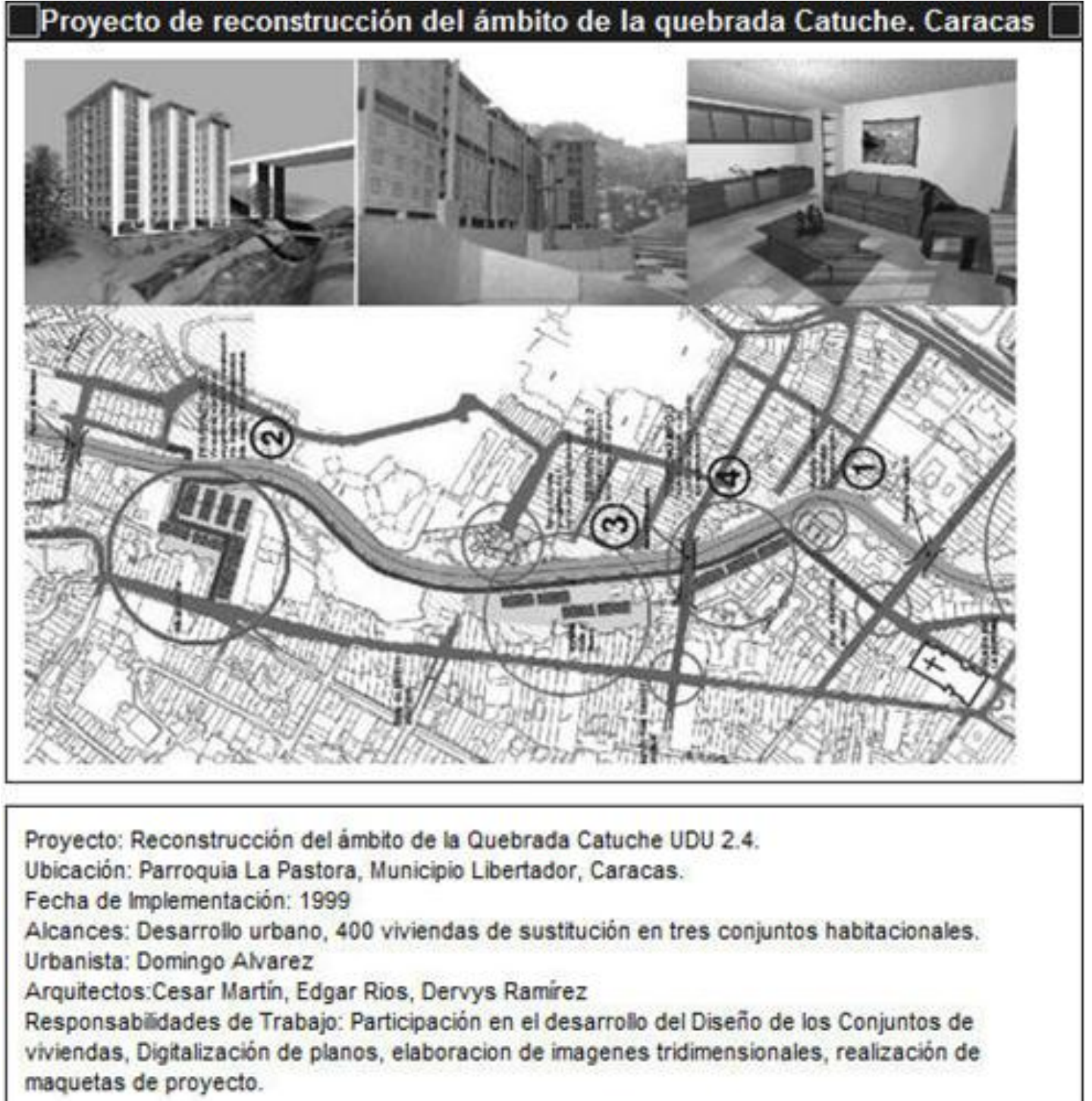

Figura 6. Proyecto de reconstrucción del ámbito de la Quebrada Catuche, Caracas. Fuente: Arquitectudarm. <http://webs.demasiado.com/dervysrm/planocatuche.htm>.

\section{La resistencia}

Hemos llegado a un punto en que ya no podemos aceptar lo que Margaret Thatcher dijo: "no hay alternativas"; debemos formular alternativas; y podemos aproximarnos a las mismas concibiendo el derecho a la ciu-

dad como una demanda popular e internacional.

Espero que nos unamos todos en esta misión. David Harvey, en el Foro Social Mundial, Belem (2009). Las intervenciones en los slums para mejorar las condiciones de la vivienda y de los barrios demuestran, de muchas formas, alternativas de solución para miles de familias en comunidades del mundo entero. Sin embargo, el desafío de la inclusión de cada slum en una habitabilidad digna de su contexto local pasa por procesos de cambio estructural de las ciudades y de las sociedades. Se trata de luchas colectivas, más allá del logro individual de los derechos económicos, sociales y culturales, correspondientes a los principios de universalidad e indivisibilidad de los derechos y convergentes en la no discriminación. Es un desafío que llevó a Henri Lefebvre (1968, p. 108) a afirmar que "el derecho a la ciudad no puede concebirse como el simple derecho de visita o de 
regreso a las ciudades tradicionales. Puede formularse solamente como derecho a la vida urbana, transformada, renovada".

Esta reformulación de la vida urbana propone mayor equidad, una situación en que la mayoría de los habitantes logren ser felices y solidarios, generando y redistribuyendo los beneficios de la ciudad para todas y todos. Somos conscientes de los desafíos de esta aspiración de justicia social; algunos la llaman quimera o ilusión. Nosotros la llamamos la praxis de una utopía indispensable para otro mundo posible. En esta gran tarea de (re)inventar condiciones del buen vivir - como lo reclaman los indígenas andinos quechuas y aymaras - es imprescindible construir estrategias globales para crear otra ciudad y otras relaciones humanas. Los movimientos sociales desempeñan en eso un importante papel a través de sus luchas cotidianas por una sociedad más igualitaria y específicamente por una ciudad más justa.

Una expresión de estas capacidades en el mundo entero, en un proceso de convergencia en el espacio del Foro Social Mundial, es ahora en 2012 la defensa de los temas urbanos en la Cumbre de los Pueblos para el Rio+20 (en Rio de Janeiro, en junio $^{25}$ y del Foro Social Urbano que se realizará en paralelo al Foro Urbano Mundial 6 de ONUHábitat (en Nápoles, en septiembre), cuyas instancias articuladoras son la Alianza Internacional de los Habitantes (AIH), la Coalición Internacional del Hábitat (HIC, por su sigla en inglés), el movimiento No-Vox y plataformas regionales como Locoa en Asia y Selavip en América Latina.

Desde hace veinte años, HIC está involucrada en este proceso, acompañando movimientos y grupos sociales, sistematizando la diversidad de los actores en la construcción del derecho a la ciudad, y avanzando a través de conquistas, derrotas y rearticulaciones (en otras palabras: aciertos, errores y recomposiciones de fuerzas), para ana- lizar y entender los cambios, las rebeliones y las propuestas que surgen de los barrios y territorios. Cada una de estas expresiones corresponde a problemas distintos, sean ellos de marginalidad, de delincuencia, de segregación, de autoconstrucción mal asistida, de estigmatización de la pobreza o de criminalización de la rebeldía. Frente a estas realidades, tenemos que difundir nuevas miradas, que entiendan las singularidades locales, respeten la diversidad y rechacen los efectos perversos que arrastran las imágenes negativas creadas por el asistencialismo y el discurso mediático. Los dos casos que presento a continuación forman parte de la publicación Ciudades para tod@s (Sugranyes y Mathivet, 2011).

\section{El movimiento Abahlali base Mjondolo (AbM) en Durban ${ }^{26}$}

Las expectativas depositadas en el fin del apartheid de las poblaciones establecidas en los suburbios de las ciudades sudafricanas, en muchos casos no han encontrado respuesta. En tiempos de lucha contra el apartheid, el derecho igualitario a la ciudad en contra del urbanismo racista era ya una de las líneas principales de la política reivindicativa de la población oprimida.

Llegado Mandela al poder, la Constitución reconoció el derecho a la vivienda; se aprobaron leyes y políticas habitacionales que impedían los desalojos de los asentamientos, defendiendo de este modo a la población urbana más vulnerable. Pero con él también se instauró un modelo económico neoliberal que contribuyó a una creciente desigualdad. En aquellos primeros años de democracia, se llevó a cabo una iniciativa de construcción de vivienda social basada en un sistema de subsidios habitacionales, que fracasó debido a las irregularidades y a la corrupción desencadenada, así como por la mala calidad de las casas y su lo-

\footnotetext{
${ }^{25}$ Para más información, véase en <http://rio20.net/>
} 
calización en guetos periféricos carentes de servicios básicos. Diez años después, en 2004, reconocidos los fallos de este sistema, se adoptó una nueva política que se enfocaba de nuevo en los asentamientos, pero ahora con una visión de integración y regeneración urbana, económica y social. A pesar de las intenciones declaradas, el estado nunca secundó realmente estas iniciativas y tiempo después retomó su discurso anterior, el mismo que dura hasta nuestros días y que aboga por la erradicación de los shack settlements (asentamientos de chabolas), que suponen una amenaza para la pequeña élite negra recientemente erigida en el poder. Una nueva segregación, por clases, era instaurada por la alta minoría política.

Ante el déficit de vivienda digna, la falta de habitabilidad de estos conglomerados precarios periféricos y las frecuentes amenazas del gobierno con un uso abusivo de la violencia, desalojos y demoliciones sin alternativa, comenzaron a resurgir algunos movimientos sociales importantes. En Durban, el Abahlali baseMjondolo (AbM) nació en 2005 a raíz del bloqueo de una carretera por los vecinos del asentamiento Kennedy Road, un área periurbana que había sido designada para ser erradicada. Este movimiento, que hoy cuenta con miembros en 36 asentamientos en toda la provincia de KwaZulu-Natal, es el mayor que ha surgido fuera de la alianza ANC (Congreso Nacional Africano, por su sigla en inglés) hasta ahora en la Sudáfrica posterior al apartheid. Sin financiamiento externo, ni ligación a ningún partido político u ONG, AbM defiende un proyecto político autónomo que se centra en luchar pacíficamente por la dignidad de los individuos, funcionando como una verdadera congregación democrática donde la población más vulnerable se manifiesta propositiva sobre su propio desarrollo.

26 Elaborado por Paula González Azcárate, a partir de Pithouse (2011).
La amenaza que este movimiento reivindicativo supone para el poder dominante se expresa en la tendencia cada vez más agresiva a la represión y difamación contra numerosos líderes del movimiento. Pese a ello, ha sido secundado por diversos medios de comunicación y ha trabajado con diferentes ONG y académicos y alcanzado numerosos logros, como la defensa de asentamientos, abastecimiento de infraestructuras, implementación de diversos proyectos sociales, fortalecimiento de la sociedad civil, etc. Uno de sus mayores éxitos ha sido la campaña de septiembre de 2007 en contra de la Ley de Asentamientos Precarios, que años después fue declarada inconstitucional por criminalizar a todas la ocupaciones de tierras ilegales. Habiendo pasado por diferentes etapas, algunas con mejor diálogo con los gobiernos locales, y trabajando junto con la comunidad en la regeneración de algunos de los asentamientos en procesos participativos, hoy desempeña una actividad sumida casi en la clandestinidad, luchando sin descanso por los derechos a una ciudad diseñada para todos.

La experiencia del movimiento AbM en Sudáfrica recorre el mundo para dar a conocer ideas y prácticas de movimientos sociales del mismo tipo, estigmatizados en la pobreza de su hábitat y criminalizados por la riqueza de su organización. Llama especialmente la atención la lucha de AbM por el respeto a su propia voz, controlando que otras instancias no hablen en nombre de ellos. Otro desafío, visto desde el rol de la academia y de la asistencia técnica, es el acompañamiento profesional de un movimiento social, contribuyendo a consolidar las capacidades y los conocimientos locales, sin apoderarse de la voz de los pobladores.

En América Latina, llevamos más tiempo que los países africanos empeñados en caminos emancipatorios conducentes a la efectividad del derecho a la ciudad y la construcción de otra ciudad. Am- 
bas son metas y estrategias estrechamente articuladas entre sí, con una lógica de continuidad en el tiempo que va desde la resistencia contra las violaciones del derecho a la vivienda y a la tierra, a la formulación de acciones para la plena implementación de ese derecho, más allá de la intervención socio-espacial en los slums. Gracias a estas iniciativas populares de luchas sociales sostenidas durante décadas, como lo vemos en el caso siguiente de Brasil, también se ha logrado en Bolivia, Ecuador y México avances pioneros en este gran desafío.

\section{El Foro Nacional de Reforma Urbana de Brasi? $^{7}$}

La trayectoria de la lucha por la reforma urbana se inició en los años sesenta, cuando los sectores progresistas de la sociedad brasileña exigían reformas estructurales en la cuestión del régimen jurídico y uso social de la tierra. Las cuestiones de la reforma urbana reaparecieron en los años que van de 1970 a 1980, un tiempo de apertura política, lenta y gradual, en que los movimientos sociales paulatinamente adquirían mayor visibilidad y relevancia política y eran capaces de construir un discurso y una práctica social marcada por la autonomía. Presentaban sus reivindicaciones como derechos, a fin de revertir las desigualdades sociales sobre la base de una nueva ética social, una propuesta que postulaba la politización de la problemática urbana, entendida como un elemento fundamental para el proceso de democratización de la sociedad brasileña.

Durante este periodo, la Iglesia Católica efectuó una gran contribución con el lanzamiento de la “Acción Pastoral y el Suelo Urbano", en la que defendía el papel social de la propiedad urbana. Se trató de un texto muy importante en la lucha por la reforma urbana.

En la lucha por la reforma de la constitución federal, entre 1985 y 1988, se creó el Movimiento Na-

\footnotetext{
${ }^{27}$ Elaboración propia, a partir de Saule (2011).
}

cional por la Reforma Urbana. En un comienzo, la lucha del Movimiento tuvo un carácter local, como la demanda por la vivienda. Pero, con el fin del régimen militar, empezó a incorporar la idea de ciudad, ciudad de todos, la vivienda más allá de la casa, la calle con asfalto, con servicios públicos, con escuela, con transporte, con derecho a una vida social. Logró articular varias organizaciones de la sociedad civil, movimientos, entidades profesionales, organizaciones no gubernamentales y sindicatos para preparar un proyecto de ley para ser incorporado en la Constitución, con el objeto de modificar el perfil de exclusión de las ciudades brasileñas. Este Movimiento define el concepto de 'reforma urbana' como una nueva ética social, que condena la ciudad como fuente de ganancia para pocos a cambio de la pobreza de muchos.

Después de la Constituyente, se organizó el Foro Nacional de Reforma Urbana (FNRU) con el objeto inmediato de presionar al Congreso para regular el Capítulo sobre política urbana. Durante arduos doce años, esta fue una de sus principales tareas, hasta la promulgación de la ley federal conocida como el Estatuto de la Ciudad (2001), un compendio de leyes que regula la política urbana de la Constitución. Este instrumento define las directrices generales que deben ser observadas por el gobierno federal, por los estados y municipios, con el objeto de garantizar el pleno desarrollo de las funciones sociales de la propiedad urbana y la ciudad, el derecho a ciudades sostenibles y el desarrollo de la gestión democrática en las ciudades.

En otro frente de lucha, el FNRU logró la creación del Fondo Nacional de Vivienda de Interés Social que, ahora, se ha transformado en el gran Programa Minha Casa, Minha Vida 2, con el propósito de producir millones de viviendas, entre las cuales un $10 \%$ se desarrolla en forma autogestionaria. Los proyectos de vivienda por autogestión están liderados por los movimientos sociales urbanos y forman parte de las banderas de lucha del FNRU, especialmente ahora, en la fase de 
preparación de los mega-eventos de la copa mundial de fútbol y de los juegos olímpicos con desalojos de favelas, o de rehabilitación de estos asentamientos de los que sobran, para incorporarlos al patrimonio turístico, como lo vemos en Río de Janeiro.

\section{Conclusiones}

El tema de los slums es, ante todo, asunto de dignidad, de respeto a las comunidades, a sus identidades, sus organizaciones y sus capacidades. Por lo tanto, se opone a la abstracción de la estadística, a la tentación de comparaciones fuera de contexto y a previsiones espeluznantes sobre el futuro de las ciudades.

Los casos aquí presentados evidencian una diversidad de contextos políticos, económicos, sociales y culturales en los cuales aparecen, perduran y cambian, a veces, los asentamientos de población marginada, excluida y vulnerable. La morfología indignante de estos hábitats presenta también todo tipo de parámetros, que cambian y normalmente evolucionan en el transcurso de los años hacia algunas mejoras, principalmente por las capacidades de producción social del hábitat. A pesar de vivir en condiciones adversas y marginalizados de la dignidad humana, los pobladores de estas barriadas, mujeres y hombres, demuestran un continuo de organización local, de avances y retrocesos, de victorias y derrotas. Estas luchas se relacionan a una infinidad de emprendimientos locales, liderados por las mujeres, que logran articularse a nivel nacional, regional y global; entre ellos, un importante abanico de redes por el derecho a la vivienda y a la tierra, y el derecho a la ciudad. Ante esta diversidad de situaciones y capacidades sociales, el concepto chabolismo-slum-bidonville viene a ser un estereotipo ambiguo. Su uso en las esferas internacionales, como la campaña Cities without Slums, tiende a justificar las erradicaciones masivas, como está ocurriendo ahora en varios países de África.
Los desafíos de la investigación sobre los asentamientos precarios de millones de pobladores en el mundo se relacionan con este vasto espectro de situaciones y orientaciones, entre las cuales no perdamos de vista los dilemas que señala Margit Mayer (2007). Estos movimientos están muy atados al discurso del compromiso ciudadano, donde el voluntarismo y el trabajo comunitario son fácilmente movilizados por la agenda neoliberal. La participación en movimientos y organizaciones sociales puede transformarse en mecanismos de cooptación de disidentes y, por lo tanto, convertir los movimientos en hacedores de consenso. Las conquistas de las organizaciones y activistas por el derecho a la vivienda pueden contribuir a mejorar las condiciones de vida en barriadas pero, a la vez, generar nuevos ciclos de inversión y, por ende, nuevas amenazas de exclusión o desalojo en contra de los habituales habitantes. Los desajustes entre la macro escala de tendencias globales y las decisiones políticas y económicas en la escala local, pueden representar avances, por ejemplo en la aplicación del presupuesto participativo; sin embargo, las políticas económicas y los recortes fiscales han mermado las capacidades de iniciativas y gobiernos locales. Desde la academia y el acompañamiento profesional de organizaciones y movimientos sociales, nos corresponde entonces analizar en profundidad los riesgos de reproducción de situaciones de marginación, producir instrumentos que faciliten intercambios entre las experiencias locales — sin confiscar la voz de los pobladores y de sus organizaciones-, identificar alternativas que contribuyan a la incidencia en nuevas políticas habitacionales y que nos sigan orientando entre las oportunidades de cambio hacia otro mundo posible, de dignidad y buen vivir, para la conquista del derecho a la ciudad. 


\section{Referencias}

ACIOLY, Claudio. Acceso al suelo y la vivienda para todos.La estrategia global de ONU-Hábitat. Vídeo. Facultad de Arquitectura y Urbanismo, Santiago de Chile, 2011. <http://www.youtube. com/watch?v=i7TWvLiJW2l>. (Consultado el 17 de septiembre de 2012).

ANGOTTI, Tom. Apocalyptic anti-urbanism: Mike Davis and his planet of slums. International Journal of Urban and Regional Research, 2006, vol. 30, issue 4, p. 961-967. $<$ http://abahlali.org/files/2007-

review\%20of\%20Planet\%20of\%20Slums.pdf>. (Consultado el 17 de septiembre 2012).

AFENAH, Afia. (Re)Clamando los derechos ciudadanos en Accre, Ghana. In SUGRANYES, Ana y MATHIVET, Charlotte (Eds.). Ciudades para tod@s. Por el derecho a la ciudad, propuestas y experiencias. $2^{\mathrm{a}}$ ed. Santiago de Chile: Habitat International Coalition (HIC), 2011, p. 169-178.

CARPIO, Patricio. El buen vivir, más allá del desarrollo: la nueva perspectiva constitucional [en línea]. In América Latina en Movimiento, Ecuador, 2008. <http://alainet.org/active/24609\& lang=es $>$. (Consultado el 17 de septiembre de 2012).

CASTEL, Robert. La montée des incertitudes. Paris: Édition Seuil, 2009. 327 p.

CYTED. II Seminario Internacional sobre mejoramiento y reordenamiento de asentamientos precarios. Programa XIV.4, MEJORHAB. Valparaíso (Chile): CYTED, 1998.

DAVIS, Mike. Planet of Slums. New York: Ed. Verso, 2006. $243 \mathrm{p}$.

LEFEBVRE, Henri. Le droit à la ville. Paris: Anthropos, 1968.

LIERNUR, Jorge Francisco. De la erradicación a la radicación. Pequeña historia de un cambio de paradigma. Revista Todavía, 2008, № 20. <http: //www.revistatodavia.com.ar/todavia25/20.arquit ectura.html>. (Consultado el 17 de septiembre de 2012).

MAYER, Margit. Contesting the Neoliberalization of Urban Governance. In Contesting Neoliberalism. New York: Urban Frontiers, 2007, p. 90115.

MUMFORD, Lewis. Historia natural de la urbanización. In Revista digital Carajillo de la Ciudad, vol. 3, 2011. <http://www.cafedelasciudades. com.ar/carajillo/8_art5.htm>. (Consultado el 17 de septiembre de 2012).

OSZLAK, Oscar. Merecer la ciudad: los pobres y el derecho al espacio urbano. Buenos Aires: Cedes/Humanitas, 1991.

PITHOUSE, Richard. Review of Mike Davis' 'Planet of Slums' [en línea]. In The Struggle for the City; Linking Struggle for the Right to the City Worldwide, 2008. <http://housingstruggles. wordpress.com/2008/06/08/mike-davis-planetof-slums/>. (Consultado el 17 de septiembre de 2012).

PITHOUSE, Richard. Abahlali base Mjondolo y la lucha popular por el derecho a la ciudad en Durban. In SUGRANYES, Ana y MATHIVET, Charlotte (Eds.). Ciudades para tod@s. Por el derecho a la ciudad, propuestas y experiencias. $2^{\mathrm{a}}$ ed. Santiago de Chile: Habitat International Coalition (HIC), 2011, p. 141-149.

RAMÍREZ, Gloria. De la Declaración Universal de los Derechos Humanos del siglo XX a la Carta de Derechos Humanos Emergentes del siglo XXI [en línea]. Barcelona: Institut de Drets Humans de Catalunya. <http://www.idhc.org/ esp/documents/CDHE/CDHE_Ramirez.pdf>

REESE, Eduardo. Planificación urbana y vivienda en América Latina: el urbanismo de la desigualdad. En Foro internacional de intercambio sobre políticas descentralizadas de vivienda y hábitat, Red Hábitat, La Paz, 2012.

RIOFRÍO, Gustavo y RODRIGUEZ, Alfredo. De invasores a invadidos. Lima: Desco, 1972.125 p. 
RODRíGUEZ, Alfredo y SUGRANYES, Ana. Los con techo. Un desafío para la política de vivienda social. Santiago de Chile: Ediciones SUR, 2005. 267 p.

SAULE, Nelson y UZZO, Karin. La trayectoria de la reforma urbana en Brasil. In SUGRANYES, Ana y MATHIVET, Charlotte (Eds.). Ciudades para tod@s. Por el derecho a la ciudad,propuestas $y$ experiencias. $2^{a}$ ed. Santiago de Chile: Habitat International Coalition (HIC), 2011, p. 261-272.

SUGRANYES, Ana y MATHIVET, Charlotte. Ciudades para tod@s. Por el derecho a la ciudad, propuestas $y$ experiencias. $2^{\mathrm{a}}$ ed. Santiago de Chile: Habitat International Coalition (HIC), 2011. 343 p.

TOLOSA, José María. Sumak Kawsay, Suma Qamaña, Buen Vivir [en línea]. In Rebelión, 2009. <www.kaosenlared.net/noticia/sumakkawsay-suma-qamana-buen-vivir>. (Consultado el 17 de septiembre de 2012).

UN-HABITAT. The Slums of the World: The face of urban poverty in the new millennium? Working Paper. Nairobi (Kenya): UN-HABITAT, Global Urban Observatory, 2003. <http://www .unhabitat.org/pmss/listltemDetails.aspx?publica tionID=1124>. (Consultado el 17 de septiembre de 2012).

VALLADARES, Eduardo. Urban Slums Reports: The case of Guatemala City, Guatemala. [en línea]. In Understading slums. Case Studies for the Global Report on Human Settlements 2003. Development Planning Unit (DPU), University College London, 2003. 23 p. $<$ http://www.ucl.ac.uk/dpuprojects/Global_Report/pdfs/Guatemala.pdf>. (Consultado el 17 de septiembre de 2012).

\section{Cita del artículo}

SUGRANYES, A. Chabolismo indignante: el hábitat de los que sobran. Hábitat y Sociedad, 2011, nº 3, p. 2749. <www.habitatysociedad.us.es>.

http://dx.doi.org/10.12795/HabitatySociedad.2011.i3.03 